\title{
FAKTOR YANG BERHUBUNGAN DENGAN KESIAPAN ANAK USIA (24 - 36 BULAN) DALAM MELAKUKAN TOILET TRAINING
}

\author{
Del Fatmawati ${ }^{1}$ Nurmala Sari ${ }^{2}$ \\ Keperawatan STIKes Fort De Kock Bukittinggi \\ delfatmawati@gmail.com
}

Submitted: 15-07-2017, Reviewer: 14-08-2017, Accepted: 15-12-2017

\begin{abstract}
ABSTRAK
Toilet training pada anak merupakan suatu cara untuk melatih anak agar mampu mengontrol dalam melakukan buang air kecil dan buang air besar, serta buang air besar pada tempatnya. Sekitar 30\% anak berumur 4 tahun, $10 \%$ anak berumur 6 tahun, 3\% anak berumur 12 tahun dan $1 \%$ anak berumur 18 tahun masih buang air kecil tidak disengaja. Penelitian ini bertujuan untuk mengetahui Faktor - Faktor Yang Berhubungan Dengan Kesiapan Anak Usia Batita (24 - 36 Bulan) Dalam Melakukan Toilet Training di PAUD Melati Perip Pepabri Jorong Giri Maju Pasaman Barat Tahun 2014.Jenis penelitian yang digunakan adalah deskriptif analitik dengan pendekatan cross sectional. Populasi yang digunakan adalah para ibu yang berjumlah 35 orang dengan sampel 35 orang dan menggunakan tehnik total sampling. Uji analisis yang digunakan adalah analisis univariat dan analisis bivariat menggunakan Chi Square atau Fisher's Exact Test. Hasil uji statistic didapatkan hubungan bermakna pengetahuan orang tua ( $\mathrm{p}=0,000$; $\mathrm{OR}=44)$, sikap orang tua $(\mathrm{p}=0,031 ; \mathrm{OR}=6,8)$ dan motivasi orang tua $(\mathrm{p}=0,016 ; \mathrm{OR}=8,5)$ dengan kesiapan batita dalam pelaksanaan toilet training di PAUD Melati Perip Pepabri Jorong Giri Maju Pasaman Barat Tahun 2014.Berdasarkan hasil penelitian dapat disimpulkan bahwa adanya pengaruh pengetahuan orang tua paling tinggi terhadap pelaksanan toilet training pada batita
\end{abstract}

Kata Kunci : Pengetahuan, Sikap, Motivasi, Toilet training

\begin{abstract}
Toilet training in a child is a way to train children to be able to take control of 'urination and defecation, and defecation in place. About 30\% children from 4 years, $10 \%$ of children from 6 years, 3\% children from 12 years and $1 \%$ children from 18 years old still pees was unintentional. This research aims to know The Factors That Related To The Preparing Of The Toddler Age Children (24-36 Months) Doing Toilet Training In PAUD Melati Perip Pepabri West Pasaman Barat In 2014This type of research is descriptive analytic with cross sectional approach. The population used is the mother of 35 people with a sample of 35 people and use the method total sampling.. Results of the test statistic obtained a Significant relationship parental knowledge $(\mathrm{p}=0.000 ;$ Or $=44)$, parent attitude $(\mathrm{p}=0,031 ; \mathrm{OR}=6.8)$ and the motivation of the parents $(\mathrm{p}=0,016$; $\mathrm{OR}=8.5)$ to toilet training prepare of the toddler in PAUD Melati Perip Pepabri West Pasaman Barat In 2014.
\end{abstract}

Keywords: Knowledge, Attitude, Motivation, Toilet Training 


\section{PENDAHULUAN}

Pembangunan kesehatan merupakan salah satu upaya untuk meningkatkan derajat kesehatan masyarakat. Pencapaian derajat kesehatan yang optimal bukan hanya menjadi tanggung jawab dari sektor kesehatan saja, namun sektor terkait lainnya seperti sektor pendidikan, sektor ekonomi, sektor sosial dan pemerintahan juga memiliki peranan yang cukup besar. Upaya pembangunan dibidang kesehatan tercermin dalam program kesehatan melalui upaya promotof, preventif, kuratif maupun rehabilitatif. Untuk mendukung upaya tersebut diperlukan ketersediaan data mengenai penduduk sebagai sasaran program pembangunan kesehatan (Kartini 2013, p.1).

Adapun penduduk sasaran program pembangunan kesehatan sangatlah beragam, sesuai dengan karakteristik kelompok umur tertentu atau didasarkan pada kondisi siklus kehidupan yang terjadi. Beberapa upaya program kesehatan memiliki sasaran ibu hamil, ibu melahirkan, dan ibu nifas sedangkan beberapa program lainnya dengan penduduk sasaran terfokus pada kelompok umur tertentu, meliputi : bayi, batita, balita, anak balita, anak usia sekolah SD, wanita usia subur, penduduk produktif, usia lanjut dan lain-lain (Kartini 2013, p.1).

Keluarga sebagai wahana utama dan pertama terjadinya sosialisasi pada anak. Karena pertama, anak kali pertama berinteraksi dengan ibunya (dan anggota keluarga lain), kedua pengalaman dini belajar anak (terutama sikap sosial) awal mula diperoleh di dalam rumah dan ketiga, keluarga sesuai peran dan fungsinya diidentikan sebagai tempat pengasuhan yang didalamnya mencakup proses sosialisasi yang sekaligus bertanggung jawab untuk menumbuh-kembangkan anggota keluarganya, dengan tidak boleh mengabaikan faktor nilai, norma dan juga tingkah laku yang diharapkan baik dalam lingkungan keluarga ataupun lingkungan yang lebih luas (masyarakat) (Istichomah 2009, p.2).

Anak adalah amanat Sang Pencipta pada orang tua, keluarga dan masyarakat. Ia harus dibimbing dan dipelihara sebagai aset masa depan. Wajah masa depan sebuah negeri dapat dilihat dari bagaimana kualitas anak-anak masa kini. Secara umum ada tiga lingkungan yang sangat memengaruhi kualitas mental dan spiritual anak, yaitu lingkungan keluarga, lingkungan sekolah, dan lingkungan sosial budaya yang berhubungan dengan nilainilai serta norma-norma yang berlaku di masyarakat, termasuk di dalamnya pengaruh televisi, buku dan media massa. Ketiga lingkungan tersebut saling menopang dalam memengaruhi perkembangan dan pembentukan karakter anak (Istichomah 2009, p.2).

Sebenarnya, lingkungan kedua dan ketiga dapat dikontrol pengaruhnya jika lingkungan pertama yakni orang tua-dalam hal ini keluarga-mampu memaksimalkan perhatiannya terhadap pengasuhan dan pendidikan anak-anak. Kita sangat paham bahwa anak adalah makhluk aktif yang tengah dalam penjelajahan mencari dunianya. Ia membutuhkan pemandu agar ia tidak salah dalam memilih jalan hidupnya. Pemandu itu tidak lain adalah orang tua dan para pendidik (guru) (Istichomah 2009, p.2).

Lima tahun pertama kehidupan anak merupakan letak dasar bagi terpenuhinya segala kebutuhan fisik, maupun psikis di awal perkembangannya, diramalkan akan dapat melaksanakan tugas-tugas perkembangan selanjutnya. Pada masa ini juga disebut-sebut sebagai masa keemasan (golden age) dalam perkembangan seorang anak, sebab diusia ini anak mengalami lompatan kemajuan 
yang menakjubkan (Hurlock 2003, Pusparini dkk 2009, p.105). Tidak ada patokan usia kapan toilet training (TT) harus dimulai. Saat yang tepat tergantung dari perkembangan fisik dan mental anak. Anak berusia dibawah 12 bulan tidak mempunyai kontrol terhadap kandung kemih dan buang air besar, 6 bulan sesudahnya ada sedikit kontrol. Antara 18 dan 24 bulan beberapa anak sudah menunjukkan kesiapan, tetapi beberapa anak belum siap sampai usia 30 bulan atau lebih (Sekartini 2009, p.2).

Riset yang dilakukan di Amerika menunjukkan usia rata-rata anak menguasai latihan toilet (menguasai tidak mengompol selama satu hari penuh) adalah usia 35 bulan bagi anak perempuan dan usia 39 bulan bagi anak laki-laki. Dan hampir $90 \%$ anak dapat mengendalikan kandung kemihnya saat siang hari yaitu pada usia 3 tahun. Sekitar 90\% anak biasanya berhenti mengompol pada usia 56 tahun. Sementara yang lainnya baru bisa melakukan beberapa tahun kemudian (Gilbert 2009, Zuraidah 2014, p.3).

Studi teranyar merekomendasikan para orang tua untuk mulai mengenalkan toilet training saat anak berusia 24-36 bulan. Anak yang baru mulai belajar menggunakan toilet di atas usia 3 tahun cenderung lebih sering mengompol hinggs usia sekolah. Sebaliknya, bila ibu mulai mengenalkan anak untuk pipis dan buang air besar di toilet sebelum ia berusia 27 bulan justru lebih sering gagal (Kompas 2010, Kartini 2013. p.2).

Toilet training merupakan cara untuk melatih anak agar bisa mengontrol buang air kecil (BAK) dan buang air besar (BAB). Penerapan toilet training pada anak oleh orangtua dipengaruhi oleh banyak faktor (Faidah 2009, p.192). Sigmund Freud cit Sunaryo (2004) dalam teori perkembangannya mengatakan bahwa anak usia 3-6 tahun termasuk dalam fase anal yaitu ditandai dengan berkembangnya kepuasan disekitar fungsi eliminasi.
Dengan mengeluarkan feses (buang air besar) timbul perasaan lega, nyaman dan puas. Kepuasan tersebut bersifat egosentrik yaitu anak mampu mengendalikan sendiri fungsi tubuhnya (Kartini 2013, p.2).

Dalam melakukan toilet training, anak membutuhkan persiapan baik secara fisik, kognitif, dan psikologis. Melalui persiapan tersebut diharapkan anak mampu mengontrol BAB dan BAK secara mandiri. Suksesnya toilet training tergantung pada kesiapan yang ada pada diri anak dan keluarga (Sholihah 2009, p.1).

Banyak anak akan menunjukkan sinyal kuat bahwa merekan sudah siap secara fisik, mental, dan emosional untuk menjalani latihan toilet training sebelum usia 3 tahun. Pada anak yang sehat, kapasitas kandung kemih akan meningkat secara signifikan di usia 2 dan 3 tahun. Dengan begitu, pada umur 3 tahun kebanyakan anak dapat menahan kencing dan tetap kering dalam waktu yang lebih lama (Gilbert 2003, Sholihah 2009, p.2).

Di Indonesia diperkirakan jumlah balita mencapai $30 \%$ dari 250 juta jiwa penduduk Indonesia, dan menurut Survey Kesehatan Rumah Tangga (SKRT) nasional diperkirakan jumlah balita yang susah mengontrol BAB dan BAK (ngompol) di usia sampai prasekolah mencapai 75 juta anak. Fenomena ini dipicu karna banyak hal, pengetahuan ibu yang kurang tentang cara melatih BAB dan BAK, pemakaian (PEMPERS) popok sekali pakai, hadirnya saudara baru dan masih banyak lainnya ( Riblat 2003, Pusparini dkk 2009, p.105).

Kualitas perkembangan anak terutama ditentukan pada usia batita (bayi usia tiga tahun) yang usia kisarannya 0-3 tahun. Kebiasaan mengompol pada anak usia di bawah usia 2 tahun masih dianggap sebagai hal yang wajar. Beberapa hasil penelitian dan literatur menyebutkan kirakira setengah dari anak usia 3 tahun masih mengompol. Kasus yang ditemukan di Indonesia anak usia 6 tahun yang masih 
mengompol sekitar $12 \%$ (Asti 2008, Faidah 2009, p.192).

Propinsi Sumatera Barat menurut kategori umur 0-4 tahun berjumlah 487.482 jiwa dengan laki-laki sebanyak 253.991 jiwa dan peremp uan 233.491

\begin{tabular}{cccc}
\hline No & Pengetahuan & Jumlah & $\boldsymbol{\%}$ \\
\hline 1. & Rendah & 9 & 25,7 \\
\hline 2. & Tinggi & 26 & 74,3 \\
\hline & Total & $\mathbf{3 5}$ & $\mathbf{1 0 0}$ \\
\hline
\end{tabular}

jiwa (BPS Proyeksi, 2010). Propinsi Sumatera Barat menurut kategori umur 0-4 tahun berjumlah 417.607 jiwa dengan lakilaki sebanyak 215.523 jiwa dan perempuan 202.084 jiwa (PSPK, 2013).

Berdasarkan hasil observasi dan wawancara didapatkan data Kabupaten Pasaman barat memiliki 35 lembaga PAUD yang tersebar dalam beberapa Kecamatan dan Jorong termasuk di Jorong Giri Maju yang memilki 3 PAUD, yaitu PAUD Kasih Ibu jumlah batita sebanyak 9 orang, kemudian PAUD Al-Muhajirin jumlah batita sebanyak 23 orang, dan PAUD Melati Perip Pepabri jumlah batita sebanyak 35 orang. Data awal yang di dapatkan di PAUD Kasih Ibu sekitar 2 orang $(23 \%)$ dari 9 orang batita masih mengompol jika tidak memakai pempers, data awal yang di dapatkan di PAUD AlMuhajirin sekitar 11 orang (49\%) dari 23 batita masih mengompol jika tidak menggunakan pempers, data awal dari PAUD Melati Perip Pepabri di dapatkan sekitar 24 orang (70\%) dari 35 batita masih mengompol jika tidak menggunakan pempers. Jadi kasus terbanyak adalah di PAUD Melati Perip Pepabri yaitu sekitar $70 \%$ batita masih mengompol jika tidak menggunakan pempers.

\section{HASIL DAN PEMBAHASAN Analisis Univariat}

Analisis univariat dilakukan berdasarkan data yang dikumpulkan dari 35 sampel. Untuk mengetahui faktor-faktor yang berhubungan dengan kesiapan batita dalam melakukan Toilet Training di PAUD Melati Perip Pepabri Jorong Giri Maju Pasaman Barat tahun 2014dengan hasil sebagai berikut:

\section{Tabel 1. DistribusiFrekuensi Pengetahuan Orang Tua PAUD Melati}

Dari tabel 1 menunjukkan bahwa lebih dari separoh orang tua $(74,3 \%)$ mempunyai pengetahuan yang tinggi tentang toilet training di PAUD Melati Perip Pepabri.

Tabel 2. Distribusi Frekuensi Sikap Orang Tua PAUD Melati MajuPasaman Barat

\begin{tabular}{clcc}
\hline No & Sikap & Jumlah & \% \\
1. & Negatif & 16 & 45,7 \\
2. & Positif & 19 & 54,3 \\
& Total & $\mathbf{3 5}$ & $\mathbf{1 0 0}$ \\
\hline
\end{tabular}

Dari tabel 2 diketahui dari 35 responden terdapat lebih dari separoh orang tua $(54,3 \%)$ mempunyai sikap positif tentang toilet training di PAUD Melati Perip Pepabri.

\section{Tabel. 3 Distribusi Frekuensi Motivasi Batita di PAUD Melati Jorong Giri Maju Pasaman Barat}

\begin{tabular}{cccc}
\hline No & Motivasi Batita & Jumlah & $\mathbf{\%}$ \\
\hline 1. & Rendah & 15 & 42,9 \\
\hline 2. & Tinggi & 20 & 57,1 \\
\hline & Total & $\mathbf{3 5}$ & $\mathbf{1 0 0}$ \\
\hline
\end{tabular}

Dari tabel 3 diketahui dari 35 responden didapatkan lebih dari separoh orang tua $(57,1 \%)$ mempunyai motivasi tinggi tentang toilet training di PAUD Melati Perip Pepabri 
Tabel 4 Distribusi Frekuensi Kesiapan

Toilet Training Batita PAUD Melati Jorong Giri Maju Pasaman Barat

\begin{tabular}{llcc}
\hline No & $\begin{array}{l}\text { Kesiapan } \\
\text { Batita }\end{array}$ & $\begin{array}{c}\text { Jumla } \\
\text { h }\end{array}$ & \% \\
\hline 1. & Tidak Siap & 12 & 34,3 \\
\hline 2. & Siap & 23 & 65,7 \\
\hline & Total & $\mathbf{3 5}$ & $\mathbf{1 0 0}$ \\
\hline
\end{tabular}

Dari tabel 4 diketahui bahwa dari 35 responden didapatkan lebih dari separoh batita $(65,7 \%)$ telah siap melakukan toilet training di PAUD Melati Perip Pepabri Jorong Giri Maju Pasaman Barat

Tabel 5.Hubungan Pengetahuan Orang Tua Dengan Kesiapan Batita Dalam Melakukan Toilet Training Di PAUDd Melati Jorong Giri Maju Pasaman Barat Tahun 2014

\begin{tabular}{|c|c|c|c|c|c|c|c|c|}
\hline \multirow{3}{*}{$\begin{array}{c}\text { Pengetahuan Orang } \\
\text { Tua }\end{array}$} & \multicolumn{4}{|c|}{ Kesiapan Batita } & \multirow{2}{*}{\multicolumn{2}{|c|}{ Total }} & \multirow{3}{*}{$\begin{array}{c}p \\
\text { value }\end{array}$} & \multirow{3}{*}{$\begin{array}{c}\text { OR } \\
(95 \% \mathrm{CI})\end{array}$} \\
\hline & \multicolumn{2}{|c|}{ Tidak Siap } & \multicolumn{2}{|c|}{ Siap } & & & & \\
\hline & $\mathrm{n}$ & $\%$ & $\mathrm{n}$ & $\%$ & $\mathrm{n}$ & $\%$ & & \\
\hline Rendah & 8 & 88,9 & 1 & 11,1 & 9 & 100 & & \\
\hline Tinggi & 4 & 15,4 & 22 & 84,6 & 26 & 100 & 0,000 & $44(4.2-454.9)$ \\
\hline Jumlah & 12 & 34,3 & 23 & 65,7 & 35 & 100 & & \\
\hline
\end{tabular}

Dari tabel 5.menunjukkan bahwa dari 9 orang tua yang memiliki pengetahuan rendah tentang toilet training terdapat 8 batita belum siap melakukan toilet training $(88,9 \%)$, sedangkan dari 26 responden yang memiliki pengetahuan tinggi terdapat 4 batita $(15,4 \%)$ tidak siap untuk melakukan toilet training. Hasil statistik menunjukkan bahwa terdapat hubungan antara pengetahuan orang tua dengan kesiapan batita dalam melakukan toilet trainig, karena $\mathrm{p}=0,000(\mathrm{p}<0,05)$. Nilai $\mathrm{OR}=44$ artinya orang tua yang mempunyai pengetahuan tinggi mempunyai kecendrungan (berpeluang) memiliki batita yang siap melakukan toilet training 44 kali dibanding orang tua yang berpengetahuan rendah di PAUD Melati Perip Pepabri Jorong Giri Maju Pasaman Barat Tahun 2014.

Ibu merupakan tokoh sentral yang akan berperan sebagai pendidik pertama dan utama dalam keluarga sehingga ibu harus menyadari untuk mengasuh anak secara

\begin{abstract}
Analisis Bivariat
Analisa bivariat dilakukan untuk mengetahui hubungan antara variabel independen dengan variabel dependen. Uji statistik penelitian ini mempergunakan Chi-Square, untuk menjelaskan hubungan antara variabel dependen dengan variabel independen dengan batas kemaknaan $\mathrm{p}=$ 0,05 , artinya bila $\mathrm{p} \geq 0,05$ maka hubungan antara variabel independen dan dependen tidak bermakna, tapi bila $\mathrm{p}<0,05$ maka hubungannya menjadi bermakna.
\end{abstract}


berpengetahuan rendah disebabkan kurangnya informasi terkait kesiapan anak dalam toilet training dan juga tidak mengerti dan paham dalam tahap perkembangan anak usia toddler sehingga aplikasi toilet training jarang dilakukan oleh ibu .Jika orang tua yang melakukan toilet training pada waktu yang tidak tepat akan menyebabkan timbulnya rasa ketakutan dan kemunduran dalam proses toileting

nya.

Tabel 6. Hubungan Sikap Orang Tua Dengan Kesiapan Batita Dalam Melakukan Toilet Training Di PAUD Melati Perip Pepabri Jorong Giri Maju Pasaman Barat Tahun 2014

\begin{tabular}{|c|c|c|c|c|c|c|c|c|}
\hline \multirow{3}{*}{ Sikap Orang Tua } & \multicolumn{4}{|c|}{ Kesiapan Batita } & \multirow{2}{*}{\multicolumn{2}{|c|}{ Total }} & \multirow{3}{*}{$\begin{array}{c}p \\
\text { value }\end{array}$} & \multirow{3}{*}{$\begin{array}{c}\text { OR } \\
(95 \% \mathrm{CI})\end{array}$} \\
\hline & \multicolumn{2}{|c|}{ Tidak Siap } & \multicolumn{2}{|c|}{ Siap } & & & & \\
\hline & $\mathrm{n}$ & $\%$ & $\mathrm{n}$ & $\%$ & $\mathrm{n}$ & $\%$ & & \\
\hline Negatif & 9 & 56,3 & 7 & 43,8 & 16 & 100 & & \\
\hline Positif & 3 & 15,8 & 16 & 84,2 & 19 & 100 & 0,031 & $6,87(1.41-33.28)$ \\
\hline Jumlah & 12 & 34,3 & 23 & 65,7 & 35 & 100 & & \\
\hline
\end{tabular}

Dari tabel 6 menunjukkan bahwa dari 16 orang tua yang memiliki sikap negatif tentang toilet training terdapat 9 batita $(56,3 \%)$ belum siap melakukan toilet training, sedangkan dari 19 responden yang memiliki sikap positif terdapat 3 batita $(15,8 \%)$ tidak siap untuk melakukan toilet training. Hasil statistik menunjukkan bahwa terdapat hubungan antara sikap orang tua dengan kesiapan batita dalam melakukan toilet trainig, karena $p=0,031$ ( $p<0,05$ ). Nilai $\mathrm{OR}=6,87$ artinya orang tua yang mempunyai sikap yang positif mempunyai kecendrungan (berpeluang) memiliki batita yang siap melakukan toilet training 6,8 kali dibanding orang tua yang memiliki sikap negatif di PAUD Melati Perip Pepabri Jorong Giri Maju Pasaman Barat Tahun 2014. Sikap merupakan kecenderungan ibu untuk bertindak atau berperilaku.

- Berdasarkan hasil penelitian bahwa sebagian orang tua batita

( $56 \%$ ) memiliki sikap negatif hal ini disebabkan karena kurang peduli terhadap dampak jika terlambat dalam melakukan toilet trainingdan malas dalam mengapilikasi kannya pada anak. Sehingga sikap yang negatif seringtercermin pada sikap dan perilaku si ibu seperti : tidak pernah mengajari dan mendampingi $\mathrm{BAB}$ dan BAK di toilet, selalu memfasilitasi untuk memakai pempers. Sejalan dengan penelitian yang dilakukan oleh hidayat (2005) bahwa Toilet training yang tidak diajarkan sejak dini akan membuat orangtua semakin sulit untuk mengajarkan pada anak ketika anak bertambah usianya. Berdasarkan asumsi peneliti sikap negatif yang dilakukan orang tua karena sebagian (ibu) orang tua sibuk dalam bekerja untuk mencukupi kebutuhan ekonomi sehingga dalam toilet training bukan sesuatu yang harus dilakukuan sehingga berdampak pada respon orang tua dalam bersikap sangatlah rendah.Sedangkan ibu yang memiliki sikap positifhanya ibu rumah tangga yang total dalam pengurusan anak tanpa bekerja dan punya waktu yang cukup untuk berlatih disamping itu ibu cukup paham jika toilet training itu sangat penting dilakukan segera karena akan berdampak sangat baik bagi anak dan perkembangan anak nantinya. 
Tabel 7. Hubungan Motivasi Orang Tua Dengan Kesiapan Batita Dalam Melakukan Toilet Training Di PAUD Melati Perip Pepabri Jorong Giri Maju Pasaman Barat

\begin{tabular}{|c|c|c|c|c|c|c|c|c|}
\hline \multirow{3}{*}{ Motivasi Batita } & \multicolumn{4}{|c|}{ Kesiapan Batita } & \multirow{2}{*}{\multicolumn{2}{|c|}{ Total }} & \multirow{3}{*}{$\begin{array}{c}p \\
\text { value }\end{array}$} & \multirow{3}{*}{$\begin{array}{c}\text { OR } \\
(95 \% \mathrm{CI})\end{array}$} \\
\hline & \multicolumn{2}{|c|}{ Tidak Siap } & \multicolumn{2}{|c|}{ Siap } & & & & \\
\hline & $\mathrm{n}$ & $\%$ & $\mathrm{n}$ & $\%$ & $\mathrm{n}$ & $\%$ & & \\
\hline Rendah & 9 & 60 & 6 & 40 & 15 & 100 & \multirow{3}{*}{0,016} & \multirow{3}{*}{$8,5(1.7-42.2)$} \\
\hline Tinggi & 3 & 15 & 17 & 85 & 19 & 100 & & \\
\hline Jumlah & 12 & 34,3 & 23 & 65,7 & 35 & 100 & & \\
\hline
\end{tabular}

Dari tabel 7 menunjukkan bahwa dari 15 motivasi batita yang rendah dalam melakukan toilet training terdapat 9 batita (60\%) belum siap melakukan toilet training, sedangkan 19 responden yang memiliki motivasi tinggi terdapat 3 batita $(15 \%)$ tidak siap untuk melakukan toilet training. Hasil statistik menunjukkan bahwa terdapat hubungan antara motivasi batita dengan kesiapan batita dalam melakukan toilet trainig, karena $\mathrm{p}=0,016$ $(\mathrm{p}<0,05)$. Nilai $\mathrm{OR}=8,5$ artinya batita yang mempunyaimotivasi yang tinggi dalam melakukan toilet training berpeluang memiliki batita yang siap melakukan toilet training 8,5 kali dibanding batita yang motivasi rendah dalam melakukan toilet training di PAUD Melati Perip Pepabri Jorong Giri Maju Pasaman Barat Tahun 2014. Motivasi adalah sebuah dorongan yang datang baik dari dalam diri maupun dari luar diri yang mempengaruhi dalam bertindak (Mauli, 2013 ). Jadi dalam latihan toilet training pada anak usia batita sangat dipengaruhi oleh motivasi dari luar yaitu orang tua. Peranan orang tua sangat penting seperti mengingatkan untuk $\mathrm{BAB} / \mathrm{BAK}$, memberi semangat dan pujian, serta memberi pendampingan untuk meningkatkan rasa percaya diri pada anak. Penelitian ini sejalan dengan penelitian (Subagiyo 2010)dimana motivasi orang tua ( $\mathrm{ibu}$ ) sangat berhubungan dengan tingkat keberhasilan anak dalam toilet training.

Menurut asumsi peneliti motivasi oleh orang tua sangat besar pengaruhnya dalam keberhasilan toilet training pada anak batita sehingga perlu adanya kesadaran orang tua untuk selalu bersabar dan memberi latihan pada anak. Jika masih ada orang tua yang masih kurang memberi motivasi hal ini disebabkan karenakurang pahamnya orang tua cara merangsang anak untuk toilet training, kurang mendampingi anak jika mereka BAB atau BAK, serta anggapan dari orang tua bahwa kurang pentingnya latihan toilet training pada anak dengan segera.

\section{SIMPULAN}

Terdapat hubungan antara pengetahuan, sikap dan motivasi orang tua dengan kesiapan batita dalam melakukan toilet trainig, Melalui toilet training dapat langsung dilatih oleh orang tua saat mereka ingin $\mathrm{BAB}$ atau BAK dirumah seperti membuat jadwal rutin untuk toilet training , sehingga anak menjadi terbiasa ketika berada diluar rumah / tanpa bersama orang tua mereka.. Disamping itu orang tua selalu memberi pendampingan pada anak baik itu memberi semangat, pujian atas keberhasilan yang dilakukan dalam toilet training, serta petunjuk tata cara $\mathrm{BAB}$ dan BAK yang benar sehingga akan memberi respon yang baik dan memupuk rasa percaya diri pada anak.dan berpengaruh pada perkembangannya.

\section{DAFTAR PUSTAKA}

Faidah, Evi Nur dkk. 2009. "Hubungan Antara Persepsi Dan Tingkat Pendidikan Terhadap Sikap Ibu Tentang Toilet Training Pada Anak 
Usia 1-3 Tahun Di Wilayah Kelurahan Kampung Sewu Jebres Surakarta". Universitas Muhammadiyah Surakarta. Diakses darihttp://publikasiilmiah.ums.ac.id/ Nurfaidahpdf [01 November 2014]

Hidayat, Alimul, Azis. 2005. "Pengantar Ilmu Keperawatan Anak 1", Cet 1. Jakarta: Salemba Medika

Istichomah. 2009. "Hubungan Tingkat Pengetahuan Ibu Asuh Dengan Pelaksanaan Toilet Training Secara Mandiri Pada Anak Usia Toodler Di TPA Citra RSU Rajawali Citra Bantul". Jurnal kesehatan surya medika yogyakarta. Diakses dari skripsistikes.files.wordpress.com/2009 108/14.pdf [03 November 2014]

Kartini, Mauli. 2013. "Faktor-Faktor Yang Mempengaruhi Ibu Dalam Mengaplikasikan Kesiapan Toilet Training Pada Anak Usia 2-4 Tahun Di Desa Miruk Kecamatan Krueng Barona Jaya Kabupaten Aceh Besar". Stikes U'Budiyah Banda Aceh. Di akses dari http://180.241.122.205/docjurnal/maul i_ kartini-jurnal.pdf $[25$ September 2014]

Notoatmodjo Soekidjo. 2005. "Metodologi Penelitian Kesehatan”, Cet. 3, Jakarta: PT Rineka Cipta

Notoatmodjo Soekidjo. 2007. "Promosi Kesehatan dan Ilmu Perilaku". Jakarta: PT Rineka Cipta

Notoatmodjo Soekidjo. 2010. "Metodologi Penelitian Kesehatan”, Cet. 5, Jakarta: PT Rineka Cipta

Nursalam, dkk. 2005. "Asuhan Keperawatan Bayi dan Anak". Jakarta: Salemba Medika
Nursalam. 2008. "konsep Dan Penerapan Metodologi Penelitian Ilmu Keperawatan". Jakarta : Salemba Medika

Subagyo, dkk. 2010. Hubungan Antara Motivasi Stimulasi Toilet Training Oleh Ibu Dengan Keberhasilan Toilet Training Pada Anak Prasekolah Jurnal Penelitian Kesehatan Suara Forikes Vol.I No.2 April 2010

Sari. Fitria . 2014 Hubungan Antara Tingkat Pengetahuan, Pendidikan Dan Sikap Ibu Terhadap Kebiasaan Toilet Training Pada Anak Pra Sekolah Di Tk Dharma Wanita Dayu Kecamatan Gondangrejo. STIKEs AIsyiyah Pekan Baru.

Sholihah, I. 2009. "Gambaran pengetahuan ibu tentang kesiapan toilet training pada anak usia 18-24 bulan di dusun pandantoyo kecamatan ngancar kabupaten kediri tahun 2009". Di akses dari http://dahsyat.com/gambaranpengetahuan-ibu-tentang-kesiapantoilet-training-pada-anak-usia-18$\%$ E2/80\%93-24-bulan.pdf September 2014]

Supartini, Y . 2004. "Buku Ajar Konsep Dasar Keperawatan Anak”. Jakarta: EGC Warner Penny \& Kelly Paula. 2007. "Mengajari Anak Pergi ke Toilet", Cet. 1. Jakarta: Arcan

Yusuf \& Nurihsan. 2006. "Landasan Bimbingan \& Konseling". Bandung: PT Remaja Rosdakarya

Zuraidah, dkk. 2014. "Hubungan Pola Asuh Orang Tua Dan Kesiapan Psikologis Anak Dengan Keberhasilan Toilet Training Pada Anak Usia Pra Sekolah Di PAUD Ar-Risalah Kota 
Lubuk Linggau Tahun 2014". Jurnal Poltekkes Palembang. Di akses dari poltekkespalembang.ac.id/ userfiles/ files/ jurnal_zuraidah_llg_baru_2.pdf [5 Desember 2014] 